\title{
Pharmacodynamic Studies of Beta Adrenergic Antagonism Induced in Man by Propranolol and Practolol
}

\author{
Gunter Bodem, H. L. Brammell, John V. Weil, and Charles A. Chidsey \\ From the Departments of Medicine and Pharmacology, University of Colorado \\ Medical Center, Denver, Colorado 80220
}

A B S T R A C T The pharmacodynamic activities of two beta adrenergic antagonists, propranolol and practolol, were compared in eight hypertensive patients. The activity of each antagonist was established in relation to its blood concentration at maximal and submaximal adrenergic blockade defined by inhibition of exercise tachycardia. Maximal inhibition of exercise tachycardia was comparable with both drugs and averaged $74 \pm 7 \%$ of the control value during drug treatment. This inhibition was achieved with a blood concentration of $2.5 \pm 0.4 \mu \mathrm{g} / \mathrm{ml}$ practolol and $0.10 \pm 0.08 \mu \mathrm{g} / \mathrm{ml}$ propranolol. The antagonist activities of these drugs against adrenergic stimulation with isoproterenol infusion indicated a much greater relative potency of propranolol against this stimulus, and in vivo estimates of $\mathrm{PA}_{2}$ values differed by more than 600 -fold. Relative antagonist activity of practolol during isoproterenol stimulation was equivalent both at cardiac (inotropic and chronotropic) and at vascular adrenergic receptors, whereas greater antagonist activity of propranolol was observed at vascular receptors than at cardiac receptors. Thus, the activity of practolol was not limited to cardiac receptors as previously suggested. Practolol did not reduce cardiac output at any dose level and the effect on resting blood pressure was small. Both practolol and propranolol had much greater hypotensive activity during exercise. These studies have defined the differing pharmacodynamic activities on the cardiovascular system of two effective beta adrenergic receptor antagonists and have established the blood levels of these antagonists necessary to achieve effective adrenergic blockade.

Dr. Bodem is a Research Fellow of the Medizinisch-Pharmazeutische Studiengesellschaft, Dr. Weil is the recipient of a Research Career Development Award from the National Institutes of Health, and Dr. Chidsey is a Burroughs Wellcome Scholar in Clinical Pharmacology.

Received for publication 29 March 1972 and in revised form 14 November 1972.

\section{INTRODUCTION}

As the therapeutic indications for pharmacologic blockade of beta adrenergic receptors are broadened, it becomes increasingly important to define the specific pharmacodynamic activity of beta adrenergic antagonists in man. This is especially the case in the hypertensive patient where beta blockade with propranolol has been shown to effectively lower blood pressure $(1,2)$. Such a response could be mediated by the adrenergic blocking activity of this drug or by its nonspecific cardiodepressant activity (3) which may be present when large amounts of the drug are administered (1).

Although the extent of pharmacologic blockade of beta adrenergic receptors always should be defined in patients receiving propranolol, this is often difficult to establish in the usual clinical study. Estimation of blockade involves an alteration of the heart rate response to intravenous isoproterenol or to exercise (4, 5 ), both of which are techniques too difficult for ready clinical applicability. However, if the extent of pharmacologic blockade were established in a group of patients and compared with dose, or better still to blood levels of the drug, one could then extend these findings to other patients similarly treated. The comparison to blood levels is particularly appropriate with propranolol where almost 10 -fold differences in blood levels can be demonstrated among patients after a standard oral dose of the drug (6).

We have examined these questions in hypertensive patients where the pharmacodynamic activity of beta blockade was compared with the blood level of drug, and have contrasted our findings with propranolol to those obtained in the same patients with a new beta adrenergic antagonist, practolol. The latter drug differs from propranolol in that it has been reported to have a greater antagonist action on beta $I$ as opposed to beta II adrenergic receptors (7). Therefore, we wished to compare further the relative activity of these two 
antagonists on both cardiac (beta I) and peripheral vascular (beta II) adrenergic receptors. The potencies of the two drugs also were evaluated in terms of their activities against two types of adrenergic stimulation, isoproterenol infusion and the adrenergic activation of muscular exercise.

\section{METHODS}

Eight patients with essential hypertension were admitted to the Clinical Research Center of the University of Colorado Medical Center where they were hospitalized during the 3 wk required for these studies. They ranged in age from 23 to $49 \mathrm{yr}$, two were female, and three were Negroes. Fully informed and written consent was obtained from these patients. During this time the patients received no other drugs and were maintained on a constant dietary intake with a sodium content which varied between 60 and $120 \mathrm{meq} /$ day among the individual patients. The patients were treated sequentially with both beta antagonists in increasing doses over 7 days. Practolol was given first in incremental doses of $25,50,100,200,400$, and $600 \mathrm{mg}$ orally at 6 -h intervals. This was followed by at least a 5 day recovery period during which time control cardiovascular responses were re-established. Thereafter, propranolol was administered in incremental doses of $10,20,40,60,80$, and $120 \mathrm{mg}$ orally at 6 -h intervals. Increases were terminated when maximum blockade was achieved or the development of bradycardia prevented further increases. Each dose level was given for $24 \mathrm{~h}$ before study. After stopping practolol blood samples, timed urine collections were made for 5-7 days to insure that all of the administered drug had been cleared from the body before the second study with propranolol.

Patients were studied daily $2 \mathrm{~h}$ after their last oral dose of beta antagonist and $1.5 \mathrm{~h}$ after their meal. At least three control measurements were made before giving antagonists in order to insure a consistent heart rate at rest and exercise during the last two measurements. Recovery measurements were made after practolol, and heart rates at rest and exercise were equivalent to control values. The heart rates and blood pressures are reported separately for this second control. Measurements were made at each drug level during incremental dosing. Venous blood was obtained for practolol and propranolol determination. Measurements of forearm blood flow, blood pressure, heart rate, and systolic time intervals were made after $15 \mathrm{~min}$ of recumbency. Then the patients' heart rate and blood pressure responses to tilt and treadmill exercise were measured. The patients walked at a $10 \%$ grade for 3-min intervals starting at $1.5 \mathrm{mph}$ and increasing to their maximal tolerable exercise level at $0.5-\mathrm{mph}$ increments. The minimal heart rate achieved with this exercise was $133 \mathrm{~min}^{-1}$. Two normal subjects (G. B. and C. A.C.) were also studied at exercise during control and propranolol administration orally. In the patients, the hemodynamic response to isoproterenol was evaluated once during the control period and once during both practolol and propranolol administration. Isoproterenol was infused in $0.89 \%$ sodium chloride solution at $0.5 \mathrm{ml} / \mathrm{min}$ starting with an initial level of $0.001 \mu \mathrm{g} / \mathrm{kg}$ per min. During a saline infusion and at the incremental dose levels maintained for $6 \mathrm{~min}$ each $(0.001$, 0.003 , to $1.0 \mu \mathrm{g} / \mathrm{kg}$ per $\mathrm{min}$ ), we measured heart rate, blood pressure, systolic time intervals, and forearm blood flow. Isoproterenol administration was increased until an increment in heart rate of $20-30 \mathrm{~min}^{-1}$ had been achieved. A minimal effective dose was considered as that amount of iso- proterenol which produced the initial responses in heart rate $(\triangle H R=20)$, in the pre-ejection period $(P E P)$ of the systolic time interval $(\triangle \mathrm{PEP}=25 \%)$, or in forearm vascular resistance $(\Delta F V R=25 \%)$, and which could be compared with the isoproterenol responses observed during administration of antagonist. In one patient only a $10 \mathrm{~min}^{-1}$ increase occurred before the development of a transient nodal arrhythmia precluded further infusion. Cardiac output was measured in seven patients during the control period and during practolol administration.

Heart rates were obtained using precordial electrodes and polygraphic recordings of the electrocardiograms which were also monitored continually on an oscilloscope. Blood pressures were obtained by a sphygmomanometric method using an electronic technique of detecting Korotkoff sounds (model 1950, Avionics, Inc., South Bend, Ind.) and recording these with the electrocardiogram. Systolic time intervals were obtained from the simultaneously recorded electrocardiogram, phonocardiogram, and the carotid pulse; they were calculated by the method of Weissler and associates and expressed as percent of normal predicted values (8). The pre-ejection period was used as the most sensitive index of contractility change. Forearm blood flow was measured using a water plethysmograph with the venous occlusion method (9). Cardiac output was measured using the indicator dilution technique (10) with a right atrial injection of $2 \mathrm{ml}$ of cardiogreen dye and sampling from an indwelling needle in the brachial artery. Blood pressure was recorded with a Clark strain gage (no. 3047) and peripheral vascular resistance calculated from cardiac output and mean blood pressure. Propranolol was measured fluorimetrically after extraction from plasma (6) and practolol was measured after extraction from plasma and urine by a fluorimetric method recently reported from this laboratory (11). Statistical analysis of the data was performed using the Wilcoxon sign rank test (12).

\section{RESULTS}

Beta receptor blockade induced by either practolol or propranolol effected a significant reduction of heart rate (Table $\mathrm{I}$ ). These responses will be examined first at the greatest pharmacologic effect which was achieved, as described in greater detail below. With practolol, a reduction of heart rate was observed only during tilt and exercise, whereas heart rate was unchanged at rest in the supine position. On the other hand, with propranolol, heart rate was reduced significantly at rest as well as during tilt and exercise. The extent of cardiac deceleration was comparable with these two adrenergic antagonists during tilt and exercise and, in the latter condition, the blocked heart rate at "maximum" exercise averaged $74 \%$ of the average control value during both practolol and propranolol $(P<0.001)$. This level of exercise was not equivalent to the estimated physiologic maximum of the patients since none of these individuals were conditioned. At minimum exercise (1.5 $\mathrm{mph}$ ), the inhibition of the tachycardia response was observed to be somewhat smaller with the average blocked heart rate representing 82 and $78 \%$ of the average control value with practolol and pro- 
TABLE I

Heart Rate Response during Maximal Blockade with Practolol and Propranolol

\begin{tabular}{|c|c|c|c|c|c|c|c|c|c|c|c|c|c|c|c|c|c|c|}
\hline \multirow[b]{3}{*}{ Patient } & & & \multicolumn{8}{|c|}{ Resting heart rate } & \multicolumn{8}{|c|}{ Exercise heart rate } \\
\hline & \multicolumn{2}{|c|}{ Dose } & \multicolumn{4}{|c|}{ Basal } & \multicolumn{4}{|c|}{ Tilt } & \multicolumn{4}{|c|}{$1.5 \mathrm{mph}$} & \multicolumn{4}{|c|}{ Maximum } \\
\hline & $\mathrm{Pc}$ & $\operatorname{Pr}$ & $\mathrm{C}_{1}$ & Pc & $\mathrm{C}_{2}$ & $\operatorname{Pr}$ & $C_{1}$ & $\mathrm{Pc}$ & $\mathrm{C}_{2}$ & $\operatorname{Pr}$ & $C_{1}$ & Pc & $\mathrm{C}_{2}$ & $\operatorname{Pr}$ & $C_{1}$ & $\mathrm{Pc}$ & $\mathrm{C}_{\boldsymbol{\varepsilon}}$ & $\dot{\mathbf{p}_{\mathrm{r}}}$ \\
\hline & \multicolumn{2}{|c|}{$m g / d a y$} & \multicolumn{8}{|c|}{$\min ^{-1}$} & \multicolumn{8}{|c|}{$\min ^{-1}$} \\
\hline S. E. & 1600 & 160 & 80 & 83 & 71 & 73 & 92 & 84 & 80 & 72 & 122 & 103 & 120 & 102 & 151 & 107 & 148 & 107 \\
\hline C. P. & 200 & 240 & 69 & 66 & 76 & 65 & 88 & 78 & 98 & 86 & 95 & 85 & 109 & 87 & 133 & 108 & 140 & 111 \\
\hline S. R. & 800 & 160 & 68 & 63 & 66 & 54 & 79 & 76 & 97 & 75 & 127 & 107 & 124 & 98 & 148 & 124 & 154 & 120 \\
\hline R. G. & 800 & 80 & 73 & 76 & 93 & 69 & 90 & 87 & 109 & 80 & 116 & 92 & 126 & 86 & 140 & 104 & 153 & 102 \\
\hline T. S. & 2400 & 480 & 81 & 68 & 77 & 59 & 92 & 73 & 94 & 67 & 117 & 81 & 111 & 82 & 163 & 103 & 158 & 111 \\
\hline P. M. & 200 & 80 & 75 & 59 & 75 & 56 & 91 & 64 & 91 & 61 & 111 & 83 & 111 & 82 & 135 & 100 & 135 & 99 \\
\hline C. F. & 1600 & 240 & 59 & 69 & 73 & 65 & 64 & 75 & 77 & 70 & 115 & 105 & 116 & 98 & 137 & 105 & 128 & 102 \\
\hline E. P. & 800 & 160 & 57 & 53 & 60 & 52 & 64 & 55 & 70 & 51 & 85 & 71 & 89 & 71 & 145 & 94 & 147 & 101 \\
\hline Mean & 1050 & 200 & 70 & 67 & 74 & $62^{*}$ & 83 & $74^{*}$ & 90 & $70^{*}$ & 111 & $91 \ddagger$ & 113 & $88 \ddagger$ & 144 & $106 \ddagger$ & 145 & $107 \ddagger$ \\
\hline
\end{tabular}

* Mean values differ significantly from control $(P<0.05)$.

$\ddagger$ Mean values differ significantly from control $(P<0.01)$.

$\mathrm{C}$, control; $\mathrm{Pc}$, practolol; $\mathrm{Pr}$, propranolol; Maximum, maximum level that the patient could be encouraged to achieve. $\mathrm{C}_{2}$ for P. M. was not obtained and value is taken from $C_{1}$.

pranolol, respectively $(P<0.05$, with each drug). A comparison of these exercise responses was made with those of two normal subjects in whom exercise to the true physiologic maximum was achieved. These studies indicated that the heart rate was comparably inhibited, as a fraction of the control value, at all exercise levels beyond that necessary to achieve a tachycardia of 125 $\min ^{-1}$ (Fig. 1). Furthermore, the percentage blockade of control tachycardia at all rates above $125 \mathrm{~min}^{-1}$ was comparable at a given dose level and it became greater as increasing doses of the antagonist propranolol were administered. There was no apparent overriding of the blockade by increasing adrenergic stimuli when maximum exercise was accomplished with control heart rate of $172 \mathrm{~min}^{-1}$; this was true even at a threshold dose of propranolol which had minimal pharmacologic effect (10 mg).

A comparison of the relative antagonist potency was made with practolol and propranolol during increasing dosages of each drug. The heart rate, expressed as a fraction of the control rate, decreased during "maximum" exercise as the level of antagonist in plasma increased during incremental dosing with these drugs (Fig. 2). The maximal blockade which was achieved in this study was equivalent with practolol and propranolol and approximated $25 \%$ of the control exercise heart rate. Although a plateau of the inhibitory response to propranolol was not seen as with practolol, from previous observations it appears that this is indeed a maximal or plateau level $(5,13)$. This maximal pharmacologic effect of the adrenergic antagonists was achieved with blood levels of practolol which averaged
$2.5 \pm 0.4 \mu \mathrm{g} / \mathrm{ml}$ and of propranolol which averaged 0.10 $\pm 0.08 \mu \mathrm{g} / \mathrm{ml}$. Thus, the potency of propranolol exceeds that of practolol by a factor of 25 , whereas the maximal effect of the two antagonists is similar. In contrast to these blood levels, the differences between the daily doses of practolol and propranolol necessary to achieve the maximal blockade differed by only a factor of 5 , $1050 \mathrm{mg} / \mathrm{day}$ for practolol and $200 \mathrm{mg} / \mathrm{day}$ for propranolol (Table I).

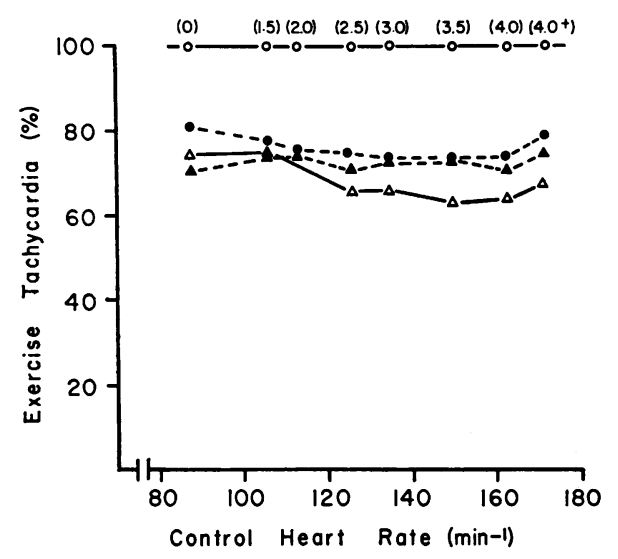

FIGURE 1 The response of heart rate to increasing amounts of propranolol at rest and during progressive exercise to the physiologic maximum heart rate in normal subject. Exercise tachycardia is expressed as a percent of the control value and plotted against the control heart rate which ranges from resting to maximum exercise values. Control (O) ; Propranolol, $10 \mathrm{mg}(\bullet), 20 \mathrm{mg}(\Delta), 40 \mathrm{mg}(\triangle)$. The values in parenthesis represent the treadmill speeds (mph) at $10 \%$ grade. $4+=20 \%$ grade.

Pharmacodynamics of Adrenergic Antagonism

749 


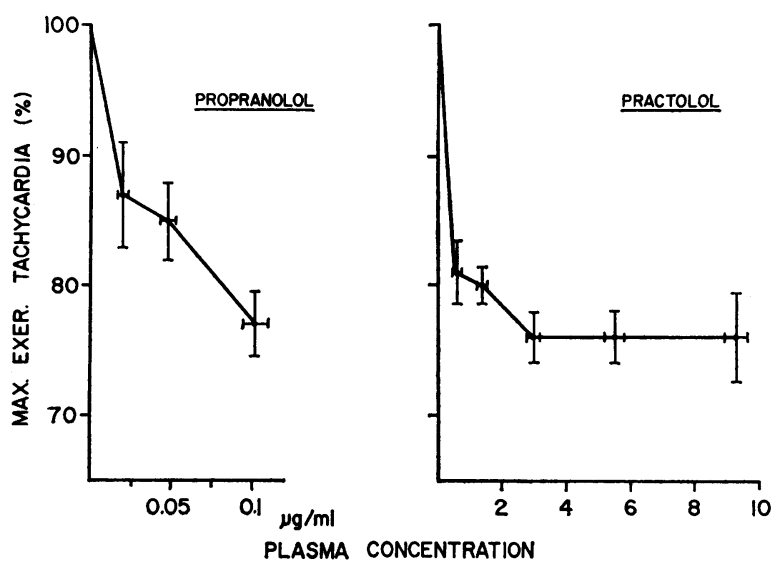

FIGURE 2 The tachycardia achieved at "maximum" exercise expressed as percent of the control value during increasing dosing of propranolol and practolol. Values are plotted against the plasma concentration of the respective antagonist. Mean values are shown with the standard error (of both response and blood level).

The antagonist activity of practolol and propranolol, in the range of doses used in these studies, was also assessed in relation to the pharmacologic adrenergic agonist, isoproterenol (Table II). The chronotropic responses of heart rate, the inotropic responses of the change in pre-ejection period, and the peripheral responses of forearm vascular resistance were all affected by these antagonists (Fig. 3). The minimal effective pharmacologic dose of isoproterenol (the minimal change in the measured variable which could be compared in control, propranolol, and practolol studies) averaged $0.015,0.012$, and $0.004 \mu \mathrm{g} / \mathrm{kg}$ per $\mathrm{min}$, respectively at the chronotropic, inotropic, and peripheral vascular receptors (Table II). The dose response was shifted consistently to the right during the administration of both of these competitive antagonists. However, the relative potency of propranolol appeared to differ from practolol in its capacity to antagonize isoproterenol at the three adrenergic receptors. Propranolol was much more effective in antagonizing the peripheral responses to isoproterenol than those of the cardiac receptors. These responses required 21.9 (chronotropic), $>25.0$ (inotropic), and $>84.8$ (vascular) times the control isoproterenol dose at these same receptors during propranolol. This differential activity was seen even when adrenergic blockade was minimal (E. P., T. S., and P. M.). In contrast practolol had a uniform effect on the receptor sites with 11.8 (chronotropic), 10.7 (inotropic), and 10.5 (vascular) times the control isoproterenol dose at chronotropic, inotropic, and peripherol receptors.

In order to compare the relative potency of practolol and propranolol as antagonists to the agonist activity of isoproterenol the shift in threshold dose of isoproterenol was related to the plasma concentration of antagonist in these patients (Fig. 4). The logarithm of the minimal effective dose displacement for the chronotropic response was plotted against the logarithm of the molar concentration of antagonist (14). It is possible that the chronotropic response during isoproterenol is influenced by vagal withdrawal as well as adrenergic stimulation from the infused agonist. However, despite our finding of the greater sensitivity of vascular receptors to isoproterenol there was little alteration of blood pressure at the minimal dose of isoproterenol which effectively increased heart rate $(\Delta \mathrm{HR}=$

TABLE II

Influence of Practolol and Propranolol on the Dose-Response Curve to Isoproterenol

\begin{tabular}{|c|c|c|c|c|c|c|c|c|c|c|c|}
\hline \multirow[b]{3}{*}{ Patient } & \multirow{2}{*}{\multicolumn{2}{|c|}{ Dose }} & \multirow{2}{*}{\multicolumn{3}{|c|}{ Minimal effective dose of Iso. }} & \multicolumn{6}{|c|}{ Relative change of threshold } \\
\hline & & & & & & \multicolumn{3}{|c|}{$\mathrm{Pc}$} & \multicolumn{3}{|c|}{$\operatorname{Pr}$} \\
\hline & $\mathbf{P c}$ & $\operatorname{Pr}$ & HR & PEP & FVR & HR & PEP & FVR & HR & PEP & FVR \\
\hline & \multicolumn{2}{|c|}{$m g / d a y$} & \multicolumn{3}{|c|}{$\mu g / \min$ per $k g$} & & & & & & \\
\hline S. E. & 1600 & 160 & 0.01 & 0.01 & 0.003 & 20 & 30 & 10 & 60 & $>30$ & 100 \\
\hline C. P. & 1600 & - & 0.03 & 0.03 & 0.003 & 10 & 3 & 10 & - & - & - \\
\hline E. P. & 800 & 160 & 0.01 & 0.01 & 0.001 & 4 & 6 & 30 & 10 & 30 & $>300$ \\
\hline S. R. & 800 & 160 & 0.006 & 0.006 & 0.003 & 6.7 & 5 & 3.3 & 33 & 50 & 10 \\
\hline R. G. & 2400 & 80 & 0.006 & 0.01 & 0.003 & 33 & 20 & 10 & 17 & 20 & 66.7 \\
\hline T. S. & 800 & 160 & 0.03 & 0.01 & 0.01 & 3.3 & 10 & 10 & 3.3 & 10 & $>20$ \\
\hline P. M. & 800 & 80 & 0.02 & 0.01 & 0.003 & 3 & 6 & 10 & 10 & - & 30 \\
\hline C. F. & 2400 & 160 & 0.01 & 0.01 & 0.003 & 10 & 10 & 10 & 20 & 10 & $>100$ \\
\hline Average & 1400 & 137 & 0.015 & 0.012 & 0.004 & 11.3 & 11.3 & 11.7 & 21.9 & $>25$ & $>89.5$ \\
\hline
\end{tabular}

Threshold dose amount of isoproterenol (Iso.) necessary to produce the initial response of the variable; relative change $=$ multiple of the control threshold dose; HR, heart rate; PEP, pre-ejection period; FVR, forearm vascular resistance. 
$\left.20 \mathrm{~min}^{-1}\right)$. The change in mean blood pressure at that dose averaged $-10 \pm 1.4( \pm S E)$ in control, $-14 \pm 2.1$ in practolol, and $+2 \pm 2 \mathrm{~mm} \mathrm{Hg}$ in propranolol periods. Thus, in control and practolol periods an equivalent vagal effect may have been present in the estimate of the minimal chronotropically effective dose of isoproterenol, but this was not present in the propranolol period. This would result only in a slight overestimation of the shift of the dose-response curve to propranolol with little or no error in that to practolol. A plot of the logarithm of the dose displacement against the blood level of antagonist allows one to make an in vivo estimate of the $\mathrm{P}_{\mathrm{A} 2}$ value, a value which represents the negative logarithm of the concentration of antagonist that just doubles the amount of agonist required to achieve a given effect. This in vivo estimate of $\mathrm{PA}_{\mathrm{A} 2}$ for practolol was 5.3 and for propranolol 8.1 indicating that $10^{-5.8}$ and $10^{-8.1} \mathrm{M}$ concentrations of these two antagonists were required to block the receptors to this extent. Thus, propranolol has 631 times the affinity for the adrenergic receptor in relation to the agonist activity of isoproterenol.

Precise evaluation of the effect of these antagonists on blood pressure could not be made because the design of the study was not directed toward this goal. However, it is apparent that the resting blood pressure, during the lowest dose of either antagonist which produced the maximal inhibition of exercise tachycardia, was also little changed by practolol (Table III). The decline in blood pressure during practolol was small and only significant in comparison to the pretreatment control. However, there was no significant reduction in pressure in comparison to the post-treatment control, when the drug had been cleared from the body and its pharmacologic effect on heart rate was absent (Table I). During propranolol only a small hypotensive response was present at rest. However, in contrast to the minimal effects on blood pressure in the resting state both drugs strikingly reduced systolic blood pressure during "maximal" exercise. When the hemodynamic response to practolol was examined at doses equal to or exceeding that necessary for maximal pharmacologic activity, little change was observed (Table IV). Thus, cardiac output was unchanged and there was only a small reduction in blood pressure. Vascular resistance and right atrial pressure were unaffected.

\section{DISCUSSION}

These studies have defined the pharmacologic effect of two adrenergic antagonists in terms of their blood concentrations using inhibition of the adrenergic component of exercise tachycardia as one criterion of this effect. Maximal inhibition of exercise tachycardia ob-
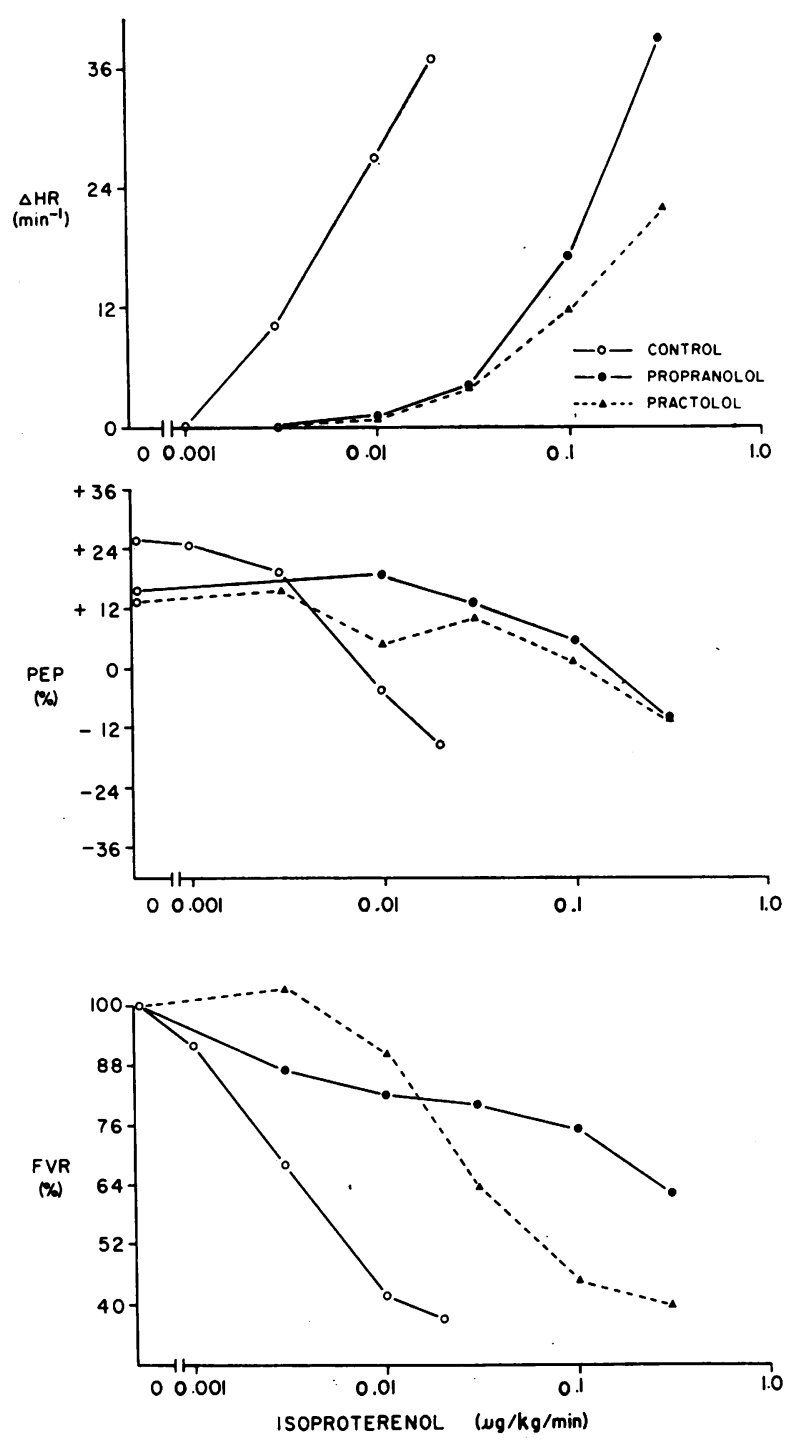

FIGURE 3 Dose-response curves to isoproterenol in a representative patient (R.G.) during the control, propranolol, and practolol periods. The change in heart rate $(\triangle H R)$ is plotted in absolute values, the pre-ejection period ( $P E P$ ) is plotted as percent of normal predicated values (8), and forearm vascular resistance (FVR) as percent of values obtained immediately before isoproterenol infusion.

served in this study was achieved with a blood level of propranolol of $0.10 \mu \mathrm{g} / \mathrm{ml}$ whereas $2.5 \mu \mathrm{g} / \mathrm{ml}$ of practolol in the blood was required for the same pharmacologic effect. The value of $0.10 \mu \mathrm{g} / \mathrm{ml}$ of propranolol is slightly higher than $0.04 \mu \mathrm{g} / \mathrm{ml}$ reported by Coltart and Shand to be necessary to achieve maximal adrenergic blockade of exercise tachycardia (13). The lower blood level of Coltart and Shand may reflect the fact that their study was done after a single oral dose of the drug when there is present a pharmacologically active, 4-hydroxy metabolite not measured by the pro-

Pharmacodynamics of Adrenergic Antagonism 


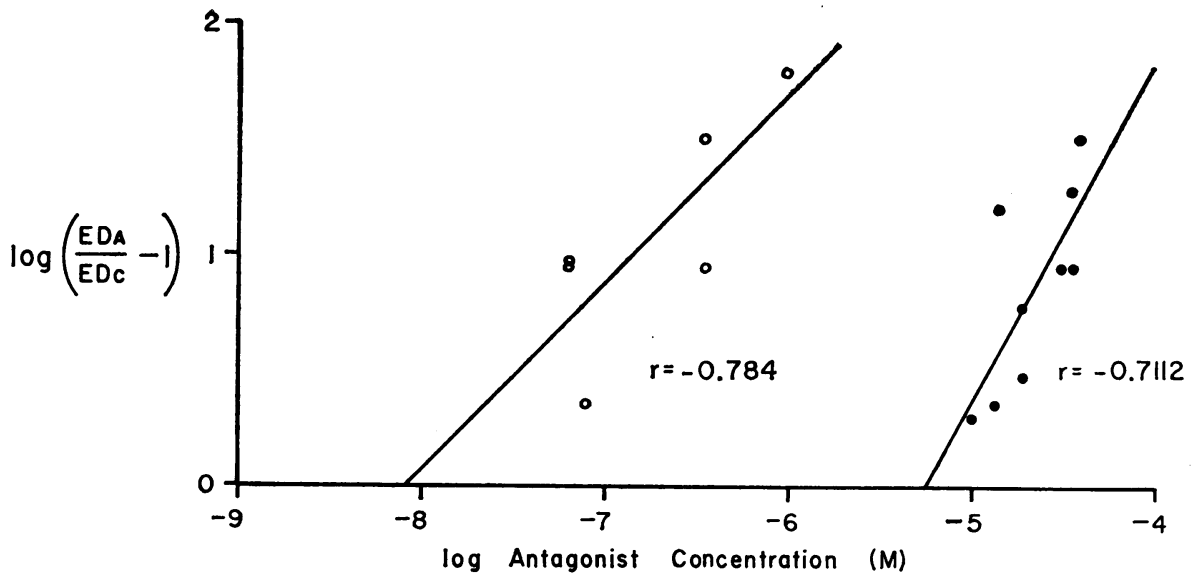

FIGURE 4 A plot of antagonist activity of propranolol (O) and practolol ( $\bullet$ ) against the concentration of drug. Antagonist activity is expressed as the logarithm of the ratio of minimum effective doses during antagonist $\left(E D_{\Delta}\right)$ and control $\left(E D_{c}\right)$ minus one. Antagonist concentration is expressed as its negative logarithm. The correlation coefficients expressed are each significant $(P<0.01)$.

pranolol method (15). Since this is apparently only formed after an initial oral dose and not after multiple doses (16), it may be that our studies involving multiple dosing may define more accurately the blood concentration-pharmacodynamic relationship with chronic therapy. In contrast to these considerations of metabolites with propranolol, no such difficulty is present with practolol since this drug is not metabolically transformed. ${ }^{1}$

Although our patients were not exercised to their true physiological maximum, heart rate at their highest exercise level was maximally inhibited to $74 \%$ of the control value by both propranolol and practolol. Practolol clearly had achieved its greatest pharmacologic effect as a plateau in the response to this drug was observed. Despite the lack of response plateau to propranolol (Fig. 2), we inferred that its maximum effect was achieved since this response was equal to that of practolol and since this was the relative degree of block-

\footnotetext{
${ }^{1}$ Bodem, G., and C. A. Chidsey. Unpublished observations.
}

ade which Coltart and Shand achieved in studies where a response plateau was demonstrated for propranolol (13). The level of blockade of exercise tachycardia in our studies was greater than that achieved by earlier experiments using maximum exercise in normal subjects (5). This then appears to be the maximal inhibition of exercise tachycardia which can be achieved with adrenergic blockade. Furthermore, this adrenergic component of exercise tachycardia appeared to be a relatively constant fraction of the control heart rate at levels of exercise which generated unblocked heart rates from $125 \mathrm{~min}^{-1}$ to the true physiologic maximum exercise level as shown in normal control subjects (Fig. 1). Therefore, the responses which were observed in the patients can be considered to be comparable within the group despite the fact that their "maximum" exercise levels differed, producing control heart rates which varied between 133 and $163 \mathrm{~min}^{-1}$.

A comparison of the pharmacologic activity of practolol and propranolol suggested a substantial difference

TABLE III

Average Blood Pressure during Maximal Blockade with Practolol and Propranolol

\begin{tabular}{|c|c|c|c|c|c|c|c|c|}
\hline & \multicolumn{2}{|c|}{ Control (1) } & \multicolumn{2}{|c|}{ Pc } & \multicolumn{2}{|c|}{ Control (2) } & \multicolumn{2}{|c|}{$\operatorname{Pr}$} \\
\hline & $\mathbf{S}$ & D & $\mathbf{S}$ & D & $\mathbf{S}$ & D & $\mathbf{S}$ & D \\
\hline $\begin{array}{l}\text { Rest } \\
\text { Exer. (max) }\end{array}$ & $\begin{array}{l}138 \pm 8 \\
196 \pm 9\end{array}$ & $\begin{array}{l}97 \pm 4 \\
79 \pm 10\end{array}$ & $\begin{array}{l}129 \pm 8 \\
143^{*} \pm 14\end{array}$ & $\begin{array}{l}89 \pm 4 \\
79 \pm 7\end{array}$ & $\begin{array}{l}130 \pm 5 \\
195 \pm 11\end{array}$ & $\begin{array}{l}90 \pm 4 \\
75 \pm 7\end{array}$ & $\begin{array}{l}120 \pm 8 \\
162^{*} \pm 13\end{array}$ & $\begin{array}{l}83 \pm 3 \\
79 \pm 5\end{array}$ \\
\hline
\end{tabular}

* Values differ significantly from control $(P<0.05)$.

Exer. (max), maximum exercise; blood pressures represent the mean and standard error of systolic (S) and diastolic (D) measurements in seven patients during the same dose of adrenergic antagonist as in Table I Pc $=1050$ $\mathrm{mg} /$ day and $\operatorname{Pr}=200 \mathrm{mg} /$ day). Control (1) obtained initially and control (2) after recovering from Pc. 
TABLE IV

Hemodynamic Data before and during Practolol

\begin{tabular}{|c|c|c|c|c|c|c|c|c|c|c|c|c|c|c|}
\hline \multirow[b]{3}{*}{ Patient } & \multirow[b]{3}{*}{ BSA } & \multirow[b]{3}{*}{ Pc conc. } & & & & $\mathbf{M}$ & \multicolumn{4}{|c|}{ Blood pressure } & & & & \\
\hline & & & \multicolumn{2}{|c|}{ Heart rate } & \multicolumn{2}{|c|}{ Cardiac output } & \multicolumn{2}{|c|}{ c } & \multicolumn{2}{|c|}{$\mathrm{Pc}$} & \multicolumn{2}{|c|}{ Vasc. res. } & \multicolumn{2}{|c|}{ R. at. pres. } \\
\hline & & & $\mathrm{C}$ & $\mathrm{Pc}$ & C & $\mathrm{Pc}$ & S/D & m & S/D & $\mathrm{m}$ & C & $\mathrm{Pc}$ & C & $\mathrm{Pc}_{\mathrm{c}}$ \\
\hline & $m^{2}$ & $\mu g / m l$ & \multicolumn{2}{|c|}{$\min ^{-1}$} & \multicolumn{2}{|c|}{ liters/min } & \multicolumn{4}{|c|}{$m m \mathrm{Hg}$} & \multicolumn{2}{|c|}{$P R U$} & \multicolumn{2}{|c|}{$m m \mathrm{Hg}$} \\
\hline S. E. & 1.49 & 13.6 & 76 & 77 & 3.7 & 4.9 & $125 / 94$ & 113 & $129 / 83$ & 103 & 30.5 & 21 & - & - \\
\hline T. S. & 2.18 & 9.7 & 82 & 84 & 7.2 & 7.2 & $140 / 90$ & 107 & $115 / 70$ & 90 & 15 & 13 & 2.5 & 0.5 \\
\hline C. F. & 2.2 & 13.2 & 79 & 69 & 6.5 & 6.7 & $173 / 105$ & 135 & $175 / 105$ & 135 & 21 & 20 & 3.5 & 3.0 \\
\hline E. P. & 2.02 & 5.9 & 56 & 50 & 4.9 & 4.6 & $245 / 140$ & 170 & $250 / 130$ & 170 & 34.7 & 37 & 3.3 & 0 \\
\hline S. R. & 1.85 & 3.9 & 65 & 59 & 5.5 & 4.9 & $128 / 80$ & 100 & $133 / 70$ & 85 & 18.2 & 17.3 & 2.5 & 5.0 \\
\hline R. G. & 1.89 & 2.6 & 65 & 73 & 5.1 & 5.0 & $150 / 90$ & 115 & $110 / 65$ & 80 & 22.5 & 16 & 1.5 & 0 \\
\hline P. M. & 2.45 & 2.6 & 89 & 79 & 7.7 & 7.5 & $143 / 93$ & 108 & $138 / 88$ & 105 & 14 & 14 & 1.5 & 0 \\
\hline Average & & 7.4 & 73 & 70 & 5.8 & 5.8 & $158 / 99$ & 121 & $150 / 87^{*}$ & $110^{*}$ & 22.3 & 19.8 & 2.5 & 1.4 \\
\hline
\end{tabular}

* Values differ significantly from control $(<0.05)$.

Vasc. res., total peripheral resistance; R. at. pres., atrial pressure; BSA, body surface area; C, control; Pc, practolol; PRU, peripheral resistance units.

in their relative potencies depending on the adrenergic stimulus which was employed. The blockade of exercise tachycardia can be assumed to involve competitive antagonism of norepinephrine since measurements have demonstrated an increase only in this catecholamine during moderate to severe exercise $(17,18)$. A potency ratio based on blood concentrations of the antagonists at maximal or even submaximal effects would suggest a 25-fold difference in the drugs when compared with norepinephrine as the presumed agonist (Fig. 2). Although this comparison is not based on molar concentrations, the small differences of molecular weights of practolol and propranolol (266 and 259) make this comparison valid. A much greater difference in relative potency was observed when the response to the agonist activity of isoproterenol was examined (Fig. 3 ). Here, analysis of the dose-response curve displacements during antagonist administration using the method of Schild (14) indicated that the in vivo estimate of $\mathrm{PA}_{\mathrm{A}}$ values for the two antagonists differed by more than 600 -fold. There are certain difficulties in defining accurately both the antagonist activity (due to potential effects of vagal withdrawal as discussed previously) as well as the actual concentration of agonist and antagonist at the receptor site. Although these difficulties make it necessary to qualify the $\mathrm{P}_{\mathrm{A} 2}$ value as only an in vivo estimate, the value still retains practical utility as a reasonable approximation of the relative pharmacodynamic potency of a given antagonist. In fact, the estimate of $\mathrm{P}_{\mathrm{A}_{2}}$ for propranolol by this in vivo method is very close to a previously reported value of 8.7 which was based on in vitro analyses using myocardial tissues (3). Thus, the in vivo estimated $\mathrm{P}_{\mathrm{A} 2}$ value defines a very much greater potency of propranolol than of practolol in antagonizing isoproterenol. Although practolol has lesser potency than propranolol in antagonizing either exercise or isoproterenol-induced tachycardia, it would appear that practolol is a more effective antagonist against the chronotropic effect of neuronally released norepinephrine than against that produced by intravenously administered isoproterenol.

A definition of the relative affinities of three adrenergic receptor sites in the cardiovascular system was derived from these studies. We can conclude that receptors in the forearm resistance vessels have a fourfold greater affinity for isoproterenol than the cardiac receptors and that the chronotropic and inotropic receptors have equivalent affinities for this adrenergic agonist. It was of interest that the antagonists had potencies relative to these receptors which were somewhat different than that which would have been predicted from previous experimental animal studies (7, 19). Using the classification of beta receptors recently proposed (20), practolol had antagonist activity at the type II adrenergic vascular receptors which was equivalent to its activity at the type I adrenergic cardiac receptors. In contrast propranolol had more activity at the type II adrenergic receptor than at the type I receptor. Thus, our evidence does not support the concept that practolol is exclusively a type I adrenergic receptor antagonist and suggests greater type II antagonism for propranolol than had been previously recognized.

We have found no reduction in cardiac output at doses of practolol which produced blood levels of 2.6$13.6 \mathrm{\mu g} / \mathrm{ml}$. Thus, no cardiodepression was observed even at doses in excess of those necessary to achieve

Pharmacodynamics of Adrenergic Antagonism

753 
a full pharmacologic effect. These data are consistent with a recent report of Leon and associates (21).

The hypotensive activity of practolol and propranolol was most apparent during exercise when significant reduction of systolic blood pressure was observed with both antagonists. At rest neither drug reduced blood pressure greatly. These studies were not designed critically to evaluate the hypotensive activity of the antagonists, but the minimal blood pressure changes which we have observed are consistant with previously published observations (21). There was an apparent decline in blood pressure during practolol, but this may have been due to an initial adaptation to the study as seen in the fall in blood pressure between the first and second control periods (Table IV). This was not the consequence of residual practolol or its pharmacologic effect because the drug had been cleared from the body and heart rates had returned to control values (Table I). In contrast to practolol, propranolol did have a small but demonstrable hypotensive effect and this difference may relate to the cardiac output reduction seen with propranolol (2). Propranolol appears to have greater antihypertensive activity when administered chronically (1). Recent observations that propranolol inhibits renin release (22) may suggest a mechanism whereby its lowers blood pressure in the hypertensive patient. Another use of propranolol in hypertension has been suggested in its combination with vasodilators (10) and practolol might be of value with such combined therapy because of its lesser activity in antagonizing the beta receptors in the arterial resistance vessels.

\section{ACKNOWLEDGMENTS}

The authors wish to acknowledge the expert technical and secretarial assistance respectively of Miss Karen Yoor and Mrs. Dale Scarborough.

This work was supported by National Institutes of Health grants HE 05722 and HE 09932, and the Ayerst Company.

\section{REFERENCES}

1. Prichard, B. N. C., and P. M. S. Gillam. 1969. Treatment of hypertension with propranolol. Br. Med. J. 1: 7.

2. Frohlich, E. D., R. C. Tarazi, H. P. Dustan, and J. H. Page. 1968. The paradox of $\beta$-adrenergic blockade in hypertension. Circulation. $37: 417$.

3. Blinks, J. R. 1967. Evaluation of the cardiac effects of several $\beta$-adrenergic blocking agents. Ann. N. Y. Acad. Sci. 139: 673.

4. Harrison, D. C., and J. R. Griffin. 1966. Metabolic and circulatory responses to selective adrenergic stimulation and blockade. Circulation. $34: 218$.
5. Epstein, S. E., B. F. Robinson, R. L. Kahler, and E Braunwald. 1965. Effects of $\beta$-adrenergic blockade on the cardiac response to maximal and submaximal exercise in man. J. Clin. Invest. 44: 1745.

6. Shand, D. G., E. M. Nuckolls, and J. S. Oates. 1970. Plasma propranolol levels in adults with observations in four children. Clin. Pharmacol. Ther. 11: 112.

7. Dunlop, D., and R. G. Shanks. 1968. Selective blockade of adrenoceptive $\beta$ receptors in the heart. $B r . J$. Pharmacol. 32 : 201.

8. Weissler, A. M., W. S. Harris, and C. D. Schoenfeld. 1969. Bedside technics for the evaluation of ventricular function in man. Am. J. Cardiol. 23: 577.

9. Wood, J. E. Limb-Segment Plethysmographs, The Veins: Normal and Abnormal Function. Little, Brown and Co., Boston. 31.

10. Gilmore, E., J. Weil, and C. Chidsey. 1970. Treatment of essential hypertension with a new vasodilator in combination with $\beta$-adrenergic blockade. N. Engl. J. Med. 282: 521 .

11. Bodem, G., and C. A. Chidsey. 1972. Simple fluorometric method for estimating practolol (1-(4-aminophenoxy-3-isopropylaminopropan-2-ol) in blood and urine. Clin. Chem. 18: 363.

12. Dixon, W. J., and T. J. Massay. 1957. Introduction To Statistical Analysis. McGraw-Hill Book Co., Inc., New York. 2nd edition. 286

13. Coltart, D. J., and D. G. Shand. 1970. Plasma propranolol levels in the quantitative assessment of $\beta$-adrenergic blockade in man. Br. Med. J. 3: 731.

14. Schild, H. O. 1947. A new scale for the measurement of drug antagonism. Br. J. Pharmacol. 2: 189.

15. Paterson, J. W., M. E. Conolly, C. T. Dollery, A. Hayes, and R. G Cooper. 1970. The pharmacodynamics and metabolism of propranolol in man. Pharmacol. Clin. $2: 127$.

16. Cleaveland, C. R., and D. G. Shand. 1972. Effect of route of administration on the relationship between $\beta$ adrenergic blockade and plasma propranolol level. Clin. Pharmacol. 13: 181.

17. Vendsalu, A. 1960. Studies on adrenaline and noradrenaline in human plasma. Acta Physiol. Scand. 49 (Suppl. 173) : 1 .

18. Chidsey, C. A., D. C. Harrison, and E. Braunwald. 1962. Augmentation of the plasma nor-epinephrine response to exercise in patients with congestive heart failure. N. Engl. J. Med. 267: 650 .

19. Levy, B. 1967. A comparison of the adrenergic receptor blocking properties of 1-(4'-methylphenyl)-2-isopropylamino-propanol- $\mathrm{HCl}$ and propranolol. J. Pharmacol. Ther. 156: 452.

20. Lands, A. M., A. Arnold, J. P. McAuliff, F. P. Ludvena, and T. G. Brown. 1967. Differentiation of receptor systems activated by sympathomimetic amines. Nature (Lond.). 214 : 597.

21. Leon, D. F., M. E. Thompson, J. A. Shaver, and R. H. McDonald, Jr. 1972. Hemodynamic effects of practolol at rest and during exercise. Circulation. 45: 46.

22. Winer, N., D. S. Chokshi, M. S. Yoon, and A. D. Freedman. 1969. Adrenergic receptor medication of renin secretion. J. Clin. Endocrinol. Metab. 29: 1168. 